\title{
Frequency Analysis of Noise Generated by Pneumatic Wheels
}

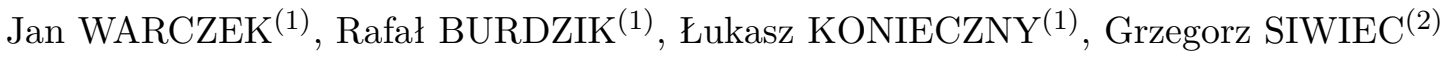 \\ (1) Faculty of Transport, Silesian University of Technology \\ Krasińskiego 8, 40-019 Katowice, Poland; e-mail: jan.warczek@polsl.pl \\ (2) Faculty of Materials Engineering and Metallurgy, Silesian University of Technology \\ Krasińskiego 8, 40-019 Katowice, Poland \\ (received March 13, 2017; accepted May 2, 2017)
}

\begin{abstract}
The dominant sources of traffic noise, which are linked directly to the vehicle, are dependent on the speed. In terms of speed of $50-120 \mathrm{~km} / \mathrm{h}$ the dominant source of noise is pneumatic wheels. The aim of the research was chosen to develop a method and experimental determination of the dominant frequency components of noise generated by the car tire. For the purpose of the study and on the basis of the analysis of the source data it was assumed that there is a relationship between the vibration of the tread elements and emitted noise, especially for low and medium frequencies. Thus, the target was set on the basis of the own method of research in the built measuring station. Based on the survey and the obtained results it can be stated that in the spectrum of the noise emitted by the tires the frequency components are dominant. Non-directional tire structure includes more frequency components which at the speed adopted in the studies are located at a greater frequency range than it is for the directional tire. In the case of a tire with a directional tread, acoustic emission energy is more associated with specific frequency components. The developed method provides results independent from the influence of the type of road surface on the acoustic emission while driving.
\end{abstract}

Keywords: noise of pneumatic tire wheels; analysis of the frequency components of noise; the station for testing tires.

\section{Introduction}

Among all kinds of noise met in everyday life the road traffic noise is at the forefront. This is mainly due to a significant increase in traffic volume which can be observed in recent years (BURDZIK, 2014; BURDZIK et al., 2013). The road noise is caused by vehicles or a "stream of vehicles" moving on the road surface.

The main factors for sound emissions are:

- operating engine, powertrain and exhaust system,

- cooperation on the tire contact with the road surface,

- disruption of air flow around the vehicle components.

A very important aspect of sound emissions is also type of road surfaces, which has a significant impact on the level of noise (ANFOSSO-LÉDÉE et al., 2007; IbARRA et al., 2017; RUSTighia et al., 2008). The share of individual sources of road noise is dependent on the speed. In terms of speed of $50-120 \mathrm{~km} / \mathrm{h}$ the dominant source of noise of modern cars is pneumatic wheels (tires). Below $50 \mathrm{~km} / \mathrm{h}$ it outweighs the noise caused by the operation of the powertrain and above $120 \mathrm{~km} / \mathrm{h}$ sounds associated with airflow around the body. Tires are an extremely important element of the vehicle as they are responsible for contact of the car with the ground, carrying the driving force and primary cushion the ride. They affect to the great extent the road safety. Currently produced tires are resistant to damage, but they are subject to fairly rapid wear process. Durability of the tires depends equally on their mechanical properties and the manner of their operation, i.e. driving style, quality of handling, etc. On the basis of tire wear we can determine the condition of the vehicle components such as suspension parts, shock absorbers, steering and braking.

As the properties of the tires influence heavily the driving safety, the process of construction of modern car tires takes into account a number of operational parameters (Michelin, 2002). The most important are the following:

- adherence (both dry and wet),

- steer ability (ability to maintain a given direction), 
- resistance to abrasion,

- low noise,

- coefficient of rolling resistance.

The parameters of the tire conducive to low noise include directional tread pattern without a confined space, the tread blocks of various shapes arranged asymmetrically and irregular, lateral grooves shaped in such a way that the inputs and outputs do not coincide with the tangent edge of the tread high flexibility of mixture from which the tread was made with correspondingly rigid skeleton of the tire. Also, the overall dimensions of the tires affect the "noisiness". The wider is the tire, the greater is the contact area with the road and thus higher noise emission. Currently approved in the EU noise limit for tires with a width of $145 \mathrm{~mm}$ is $72 \mathrm{~dB}(\mathrm{~A})$, but for the tires above $215 \mathrm{~mm}$ it is $76 \mathrm{~dB}(\mathrm{~A})$.

\section{Research problem}

In the case of most cars tires interaction with the road surface is the main source of noise at speeds above $50 \mathrm{~km} / \mathrm{h}$ while for commercial vehicles above $70 \mathrm{~km} / \mathrm{h}$. The specified speed values are determined based on statistical surveys and may vary slightly for different vehicles depending on the time of use, weight and condition of the vehicle. The main mechanisms responsible for the formation of sound while rolling the wheel through the air on the road surface may include the following:

- vibrations caused by impact of the tread elements of the road surface and their mutual detachment at the edge of the track cooperation of the tire with the road,

- mechanical vibrations of the tread band of the tire caused by design features such as variable curvature of the tread, the tread surface waviness and the heterogeneity of the material, periodically variable rigidity of the tread resulting from the applied carvings,

- vibrations of sidewalls of the tire, caused by the deformation of the tire in the contact zone with the road surface,

- vibrations of the tread elements to stimulate air trapped in the channels formed by the grooves of the tread - possible resonance of the air in the grooves of the tread on the borders of a trace of the tire contact with the road surface,

- the effect of pumping air through the closed spaces within the surface of the tread which, due to load increase change volume, the greatest effect observable in the end zone of cooperation trace,

- Helmholtz resonance caused by changes in air pressure located in the grooves of the tread leaving the zone of contact with the surface and the tire inner torus,
- turbulence of the air flowing over the tire due to the impact of movement of the tire relative to the surrounding air,

- breaking adhesive micro-connections generated within the trace of contact due to the adhesion of the rubber compound of the tread and the road surface (BURDzIK, 2014; CABAN et al., 2014; CiOCH et al., 2013; DĄBROWSKI et al., 2015; Rustighia et al., 2008).

The goal of the research was adopted to develop methods and experimental determination of the dominant frequency components of noise generated by the tire. For the purpose of the study it was assumed on the basis of the analysis of the source data, that there is a relationship between the vibration of the tread elements and emitted noise, especially for low and medium frequencies. This relationship is particularly important for the frequency corresponding to the pitch of the tread. For example, in the case of typical tires of passenger cars, the frequency related to the pitch of the tread is in the range of 0.5 to $1 \mathrm{kHz}$ (for a speed of $70 \mathrm{~km} / \mathrm{h}$ ). For most tires turned over smooth surfaces there is a close relationship between the position of some local maxima in the spectrum of the noise and speed of rolling. This speed affects in a proportionate manner to the frequency of extortion from the tread elements.

Other causes of noise emitted by rolling tire are less important to the global emission of noise. Often they depend on the radial vibration of the tread. Among other phenomena that may affect the generation of tire noise, the most important are the following: the effect of the corner, the absorption of sound by the road surface and impedance matching.

The effect of the corner has a close relationship with the shaping of geometric reflective surfaces near the entrance and exit from the tire contact patch. It increases the sound output in the direction towards the front and rear tires and is largely dependent on the width of the tire.

The sound absorption is related to the porosity of the surface or the tire, which reduces the compression of the air in the tread grooves and hinders the formation of resonance phenomena. Absorption indirectly affects the efficiency of sound generation by the aerodynamic mechanisms. The phenomenon of the absorption occurring largely can virtually eliminate the effect of the corner, pumping or resonant vibrations of air columns in the closed grooves of the tread. It has to be taken into account that a significant noise absorption by porous surfaces is presented in selected frequency ranges. As a result, the sounds of the noise components in some bands will be absorbed more than others.

Impedance matching is particularly important for the effectiveness of mechanisms that are related to the mutual impacts of elements of the tire and the road surface. On very hard surfaces (e.g. cement concrete) noise generated by the tires is much higher than on flexible surfaces (asphalt, rubber surfaces). 


\section{Research method and results}

The main methods for testing emission sound of car tires include attachment and drum coast-by method. The own method of research (based on the measurement station) was adopted and is shown in Fig. 1.

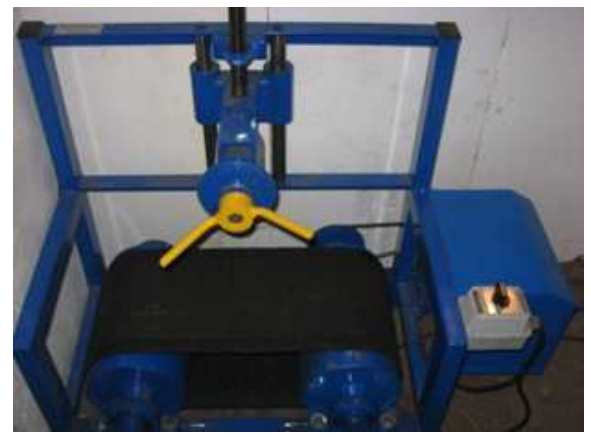

Fig. 1. The measurement station of the acoustic emission testing of tires.

Acoustic emission testing of tires was carried out in a specially prepared room, which acoustic parameters were verified experimentally. The room is dedicated to test/measure noise of pneumatic tire wheels, analysis of the frequency components of noise, the station for testing tires for research had a rectangular shape with dimensions of $7 \times 14 \mathrm{~m}$. The station was set so that the distance from the nearest obstacle reflecting the sound was at least $2.5 \mathrm{~m}$ (Fig. 2).

Prior to measurement of tires noise studies to determine the suitability of an area for research were performed. The background noise was also examined.

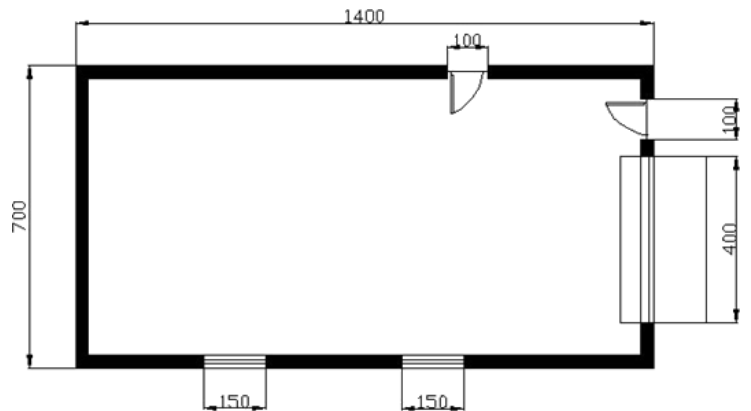

Fig. 2. Scheme of the room in which the research was conducted.

Noise measurement of machine, measured in a room dedicated to the research, and outside the room showed that the average difference is $2.4 \mathrm{~dB}$. Based on these studies it was found that the room was suitable for testing. The index value defines the environmental derogation of the research of the ideal conditions for a free field according to PN-EN ISO 3746 which should not exceed $7 \mathrm{~dB}$.

The second amendment, which was included in the study, was the influence of background noise. Assumptions adopted in the study were in accordance with PN-EN ISO 11201.

For the purposes of the research 5 points were determined. Measuring microphone was set successively in the individual measuring points. Measuring points were located at a distance of $0.25 \mathrm{~m}$ from the sound source at a height of $0.51 \mathrm{~m}$, on the set of semicircle. The view of the test station and the location of the measurement points are shown in Fig. 3. It should be a)

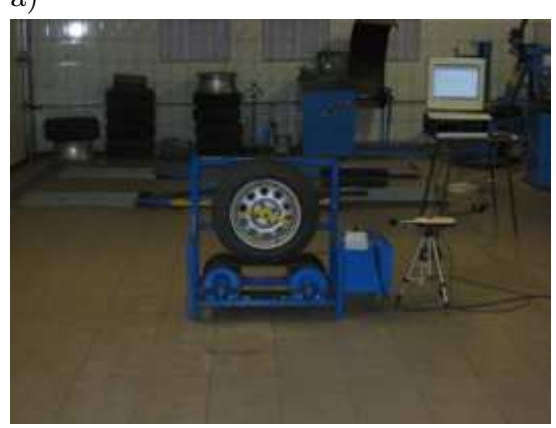

d)

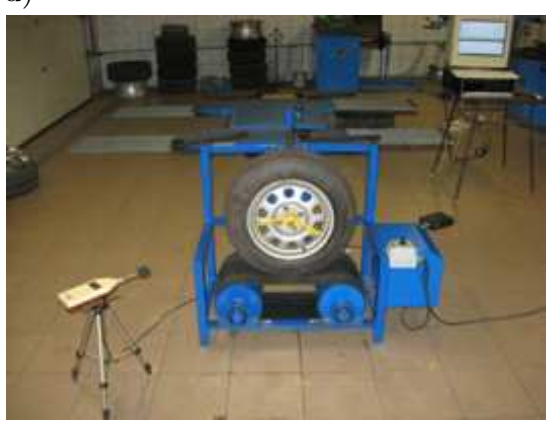

b)

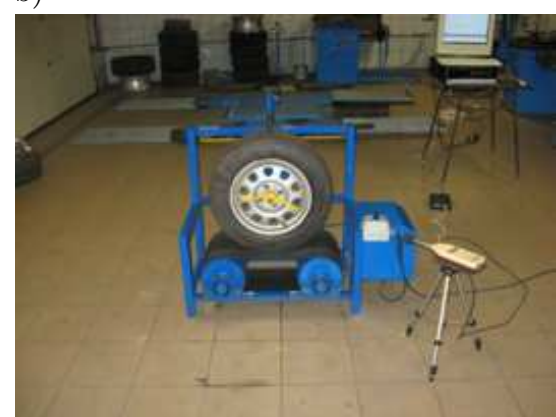

c)

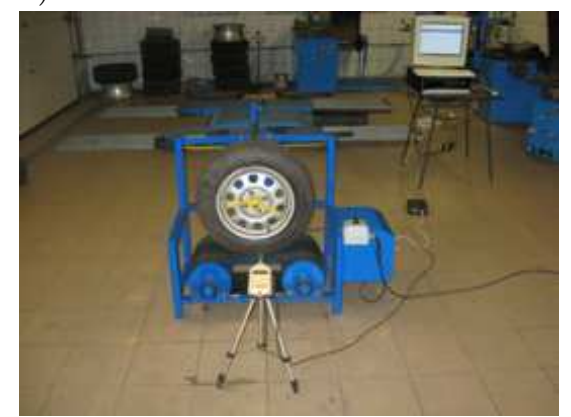

e)

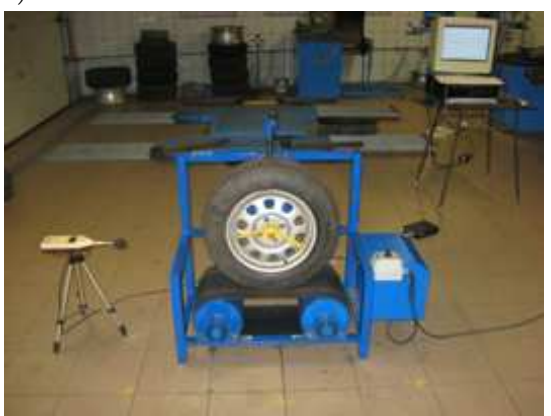

Fig. 3. Distribution of measuring points: a) measuring point No. 1, b) measuring point No. 2, c) measurement point No. 3, d) measuring point No. 4, e) measuring point No. 5, and the picture. 
noted that the results for the measuring point No. 1 are prone to errors caused by the proximity of the electric motor.

The used measuring circuit consisted of a SON 50 sound measurer cooperating with the card data acquisition. Measuring circuit consisted of the elements shown in Fig. 4.

SON-50 data acquisition MDAQ-Lite

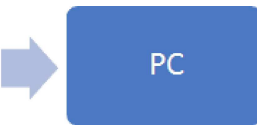

Fig. 4. Scheme of measuring circuit.

In the study measurements of acoustic emission of tires used in vehicles were carried out. To evaluate the effect of the pressure of the tire on noise emission research was conducted on tires with normal pressure and over- and reduced pressure. Tests were conducted at a constant linear speed of $26.3 \mathrm{~km} / \mathrm{h}$. In the research two types of tires were used: non-directional and directional. In Tables 1-6 there are results of research showing the dependence of the effect of tire pressure on the noise level, understood as a global measure of noise $\left(L_{\mathrm{AS}}\right.$ - sound level - correction $\mathrm{A}$, time constant slow; $L_{\mathrm{ASMX}}$ - maximum value of sound level - correction $\mathrm{A}$, time constant slow; $L_{\mathrm{ASMN}}$ minimum sound level - correction A, time constant slow; $L_{\text {Aeq }}$ - equivalent sound level - correction $\mathrm{A} ; L_{\mathrm{CPk}}$ - maximum value of sound level, time constant slow; $L_{\mathrm{CMPk}}-$ maximum value of sound level; $L_{\mathrm{EX}, 8}$ - eight-hour exposure level; $L_{\mathrm{AE}}$ - exposure sound level - correction A).

Table 1. The noise level of the non-directional tire for pressure of $0.1 \mathrm{MPa}$.

\begin{tabular}{|c|c|c|c|c|c|c|c|c|}
\hline & $L_{\mathrm{AS}}$ & $L_{\mathrm{ASMX}}$ & $L_{\mathrm{ASMN}}$ & $L_{\text {Aeq }}$ & $L_{\mathrm{CMPk}}$ & $L_{\mathrm{CPk}}$ & $L_{\mathrm{EX}, 8}$ & $L_{\mathrm{AE}}$ \\
\hline 1 & 70.1 & 70.1 & 70.1 & 69.8 & 89.5 & 88.7 & 69.8 & 75.8 \\
\hline 2 & 74.1 & 74.1 & 74.1 & 74.4 & 91.0 & 89.0 & 74.4 & 79.4 \\
\hline 3 & 76.5 & 76.5 & 76.6 & 76.7 & 91.3 & 90.9 & 76.7 & 83.7 \\
\hline 4 & 74.9 & 74.9 & 74.4 & 74.9 & 89.3 & 86.3 & 74.9 & 82.1 \\
\hline 5 & 76.8 & 77.1 & 76.4 & 77.1 & 93.3 & 92.8 & 77.1 & 86.4 \\
\hline
\end{tabular}

Table 2. The noise level of the non-directional tire for pressure of 0.2 MPa.

\begin{tabular}{|c|c|c|c|c|c|c|c|c|}
\hline & $L_{\mathrm{AS}}$ & $L_{\mathrm{ASMX}}$ & $L_{\mathrm{ASMN}}$ & $L_{\mathrm{Aeq}}$ & $L_{\mathrm{CMPk}}$ & $L_{\mathrm{CPk}}$ & $L_{\mathrm{EX}, 8}$ & $L_{\mathrm{AE}}$ \\
\hline 1 & 69.6 & 69.6 & 69.6 & 69.1 & 88.6 & 90.4 & 69.1 & 79.5 \\
\hline 2 & 74.6 & 74.8 & 74.3 & 74.7 & 92.3 & 92.3 & 74.7 & 83.6 \\
\hline 3 & 76.5 & 76.5 & 76.6 & 76.7 & 95.3 & 92.4 & 76.7 & 83.7 \\
\hline 4 & 74.5 & 74.5 & 74.2 & 74.4 & 92.0 & 91.3 & 74.4 & 84.6 \\
\hline 5 & 77.3 & 77.3 & 77.1 & 79.0 & 94.9 & 92.8 & 77.4 & 85.6 \\
\hline
\end{tabular}

Table 3. The noise level of the non-directional tire for pressure of $0.3 \mathrm{MPa}$.

\begin{tabular}{|c|c|c|c|c|c|c|c|c|}
\hline & $L_{\mathrm{AS}}$ & $L_{\mathrm{ASMX}}$ & $L_{\mathrm{ASMN}}$ & $L_{\text {Aeq }}$ & $L_{\mathrm{CMPk}}$ & $L_{\mathrm{CPk}}$ & $L_{\mathrm{EX}, 8}$ & $L_{\mathrm{AE}}$ \\
\hline 1 & 60.2 & 60.2 & 62.7 & 60.4 & 79.1 & 85.1 & 63.4 & 79.5 \\
\hline 2 & 73.4 & 73.4 & 72.3 & 72.5 & 91.0 & 86.1 & 72.5 & 85.4 \\
\hline 3 & 75.5 & 75.5 & 75.3 & 75.5 & 92.1 & 92.1 & 75.5 & 84.0 \\
\hline 4 & 72.6 & 72.9 & 72.1 & 72.8 & 80.7 & 80.7 & 72.8 & 82.4 \\
\hline 5 & 75.1 & 75.1 & 74.2 & 74.6 & 94.1 & 93.5 & 74.6 & 85.0 \\
\hline
\end{tabular}

Table 4. The noise level of the directional tire for pressure of $0.1 \mathrm{MPa}$.

\begin{tabular}{|c|c|c|c|c|c|c|c|c|}
\hline & $L_{\mathrm{AS}}$ & $L_{\mathrm{ASMX}}$ & $L_{\mathrm{ASMN}}$ & $L_{\mathrm{Aeq}}$ & $L_{\mathrm{CMPk}}$ & $L_{\mathrm{CPk}}$ & $L_{\mathrm{EX}, 8}$ & $L_{\mathrm{AE}}$ \\
\hline 1 & 66.3 & 68.2 & 66.9 & 67.6 & 76.1 & 83.4 & 67.6 & 73.6 \\
\hline 2 & 73.1 & 73.1 & 71.4 & 72.2 & 89.7 & 89.4 & 72.2 & 82.2 \\
\hline 3 & 75.5 & 75.5 & 75.5 & 75.7 & 90.4 & 89.8 & 75.7 & 80.5 \\
\hline 4 & 74.9 & 74.9 & 74.9 & 75.4 & 91.3 & 89.3 & 75.4 & 82.4 \\
\hline 5 & 76.4 & 76.6 & 76.4 & 76.7 & 95.3 & 92.3 & 76.7 & 83.6 \\
\hline
\end{tabular}


Table 5. The noise level of the directional tire for pressure of $0.2 \mathrm{MPa}$.

\begin{tabular}{|c|c|c|c|c|c|c|c|c|}
\hline & $L_{\mathrm{AS}}$ & $L_{\mathrm{ASMX}}$ & $L_{\mathrm{ASMN}}$ & $L_{\mathrm{Aeq}}$ & $L_{\mathrm{CMPk}}$ & $L_{\mathrm{CPk}}$ & $L_{\mathrm{EX}, 8}$ & $L_{\mathrm{AE}}$ \\
\hline 1 & 66.3 & 68.2 & 66.9 & 66.5 & 87.8 & 88.7 & 66.5 & 78.5 \\
\hline 2 & 70.7 & 70.7 & 71.4 & 71.0 & 87.7 & 86.8 & 71.0 & 79.6 \\
\hline 3 & 73.0 & 73.3 & 73.0 & 73.2 & 88.7 & 87.9 & 73.2 & 76.7 \\
\hline 4 & 72.3 & 72.3 & 71.8 & 72.2 & 83.9 & 83.9 & 72.2 & 80.2 \\
\hline 5 & 75.8 & 75.8 & 74.9 & 75.4 & 93.5 & 92.3 & 75.4 & 85.4 \\
\hline
\end{tabular}

Table 6. The noise level of the directional tire for pressure of $0.3 \mathrm{MPa}$.

\begin{tabular}{|c|c|c|c|c|c|c|c|c|}
\hline & $L_{\mathrm{AS}}$ & $L_{\mathrm{ASMX}}$ & $L_{\mathrm{ASMN}}$ & $L_{\mathrm{Aeq}}$ & $L_{\mathrm{CMPk}}$ & $L_{\mathrm{CPk}}$ & $L_{\mathrm{EX}, 8}$ & $L_{\mathrm{AE}}$ \\
\hline 1 & 60.2 & 60.2 & 66.9 & 60.4 & 85.5 & 82.7 & 60.4 & 69.4 \\
\hline 2 & 69.3 & 69.8 & 69.3 & 69.1 & 86.8 & 86.1 & 69.1 & 78.9 \\
\hline 3 & 72.4 & 72.4 & 72.5 & 72.6 & 87.7 & 85.4 & 72.6 & 74.8 \\
\hline 4 & 71.6 & 71.6 & 71.5 & 71.8 & 85.3 & 78.9 & 71.8 & 79.9 \\
\hline 5 & 73.2 & 73.2 & 72.5 & 73.2 & 92.0 & 89.6 & 73.2 & 81.1 \\
\hline
\end{tabular}

As the starting material to identify the frequency of components of the noise generated by the tire, the acoustic pressure signals were used. A sample recorded course of changes of acoustic pressure for the tested tire at nominal pressure and the corresponding frequency spectrum are shown in Fig. 5.

The dominant frequency components are in the range up to $4000 \mathrm{~Hz}$, and therefore the scope of the analysis was limited to this frequency. In order to identify the dominant frequency components masked by external disturbances the signal averaging was applied. This was followed by the averaging procedure for the asynchronous spectra, which was designed to minimize the impact of random measurement noise (BYOUNG et al., 2007; CABAn et al., 2014; Katunin, 2016). The method determining the averaged power spectral density distributions can be defined as follows:

$$
S(f)_{\text {sum }}=\frac{1}{k} \sum_{i=1}^{k} S(f)_{i},
$$

where

$$
S(f)_{i}=\int_{-\infty}^{\infty} R(\tau) \mathrm{e}^{-2 \pi f \tau} \mathrm{d} \tau
$$

is power spectrum density, $R(\tau)$ is autocorrelation function of acoustic pressure signal.
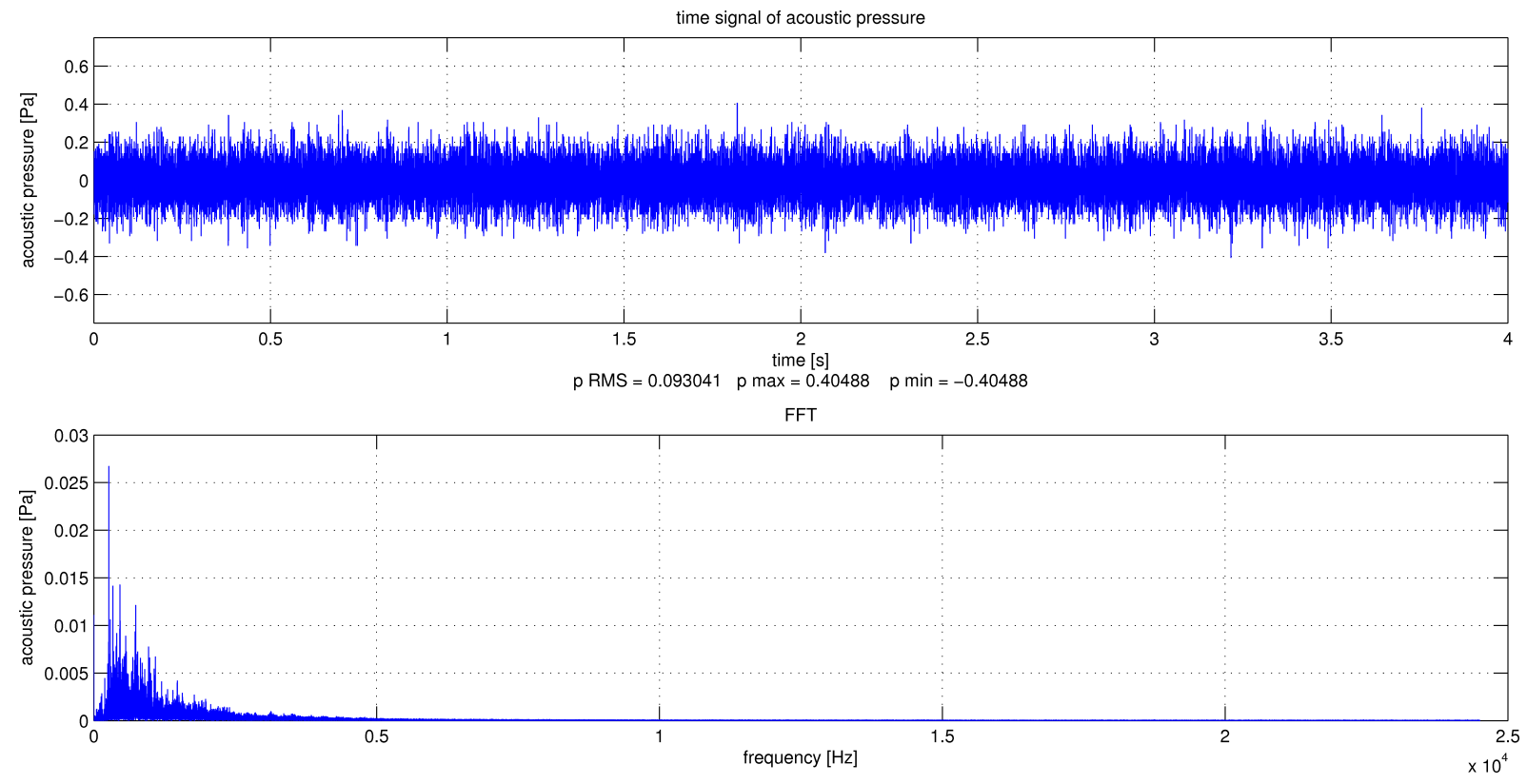

Fig. 5. An example of the acoustic pressure course and its spectrum. 
Examples of the partial results of the applied procedure of asynchronous averaging signals of acoustic pressures recorded at the same measuring point are shown in Figs. 6 and 7.
On the basis of dependence 1 averaged asynchronous spectral power density of noise mitted from the tire-running track measuring station was designated. The results shown in Figs. 8-13 were obtained

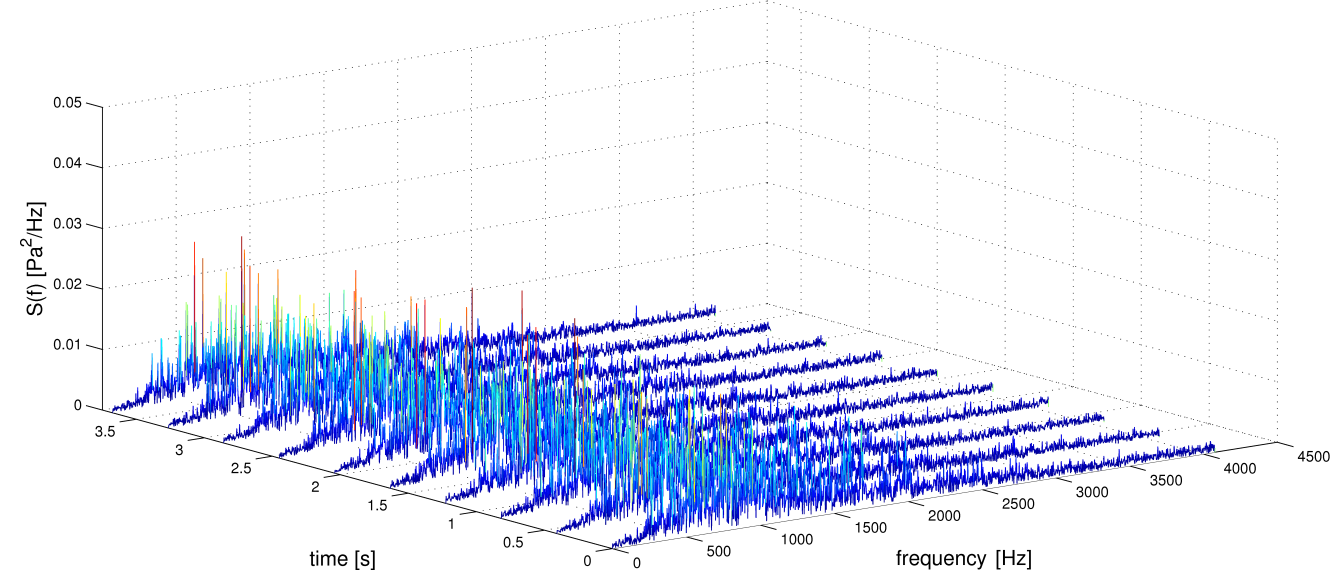

Fig. 6. Power spectrum density determined for the subsequent parts of the signal of acoustic pressure obtained for tires with non-directional tread pattern.

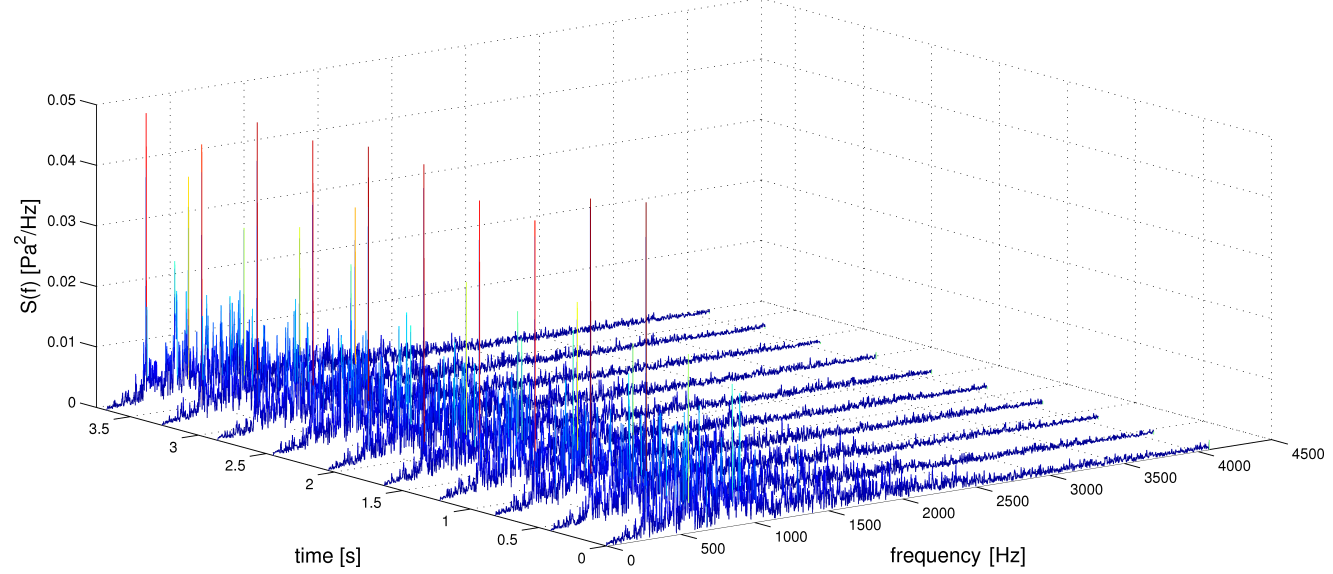

Fig. 7. Power density spectrum designated for subsequent parts of the signal of acoustic pressure obtained of the tire with a directional tread pattern.

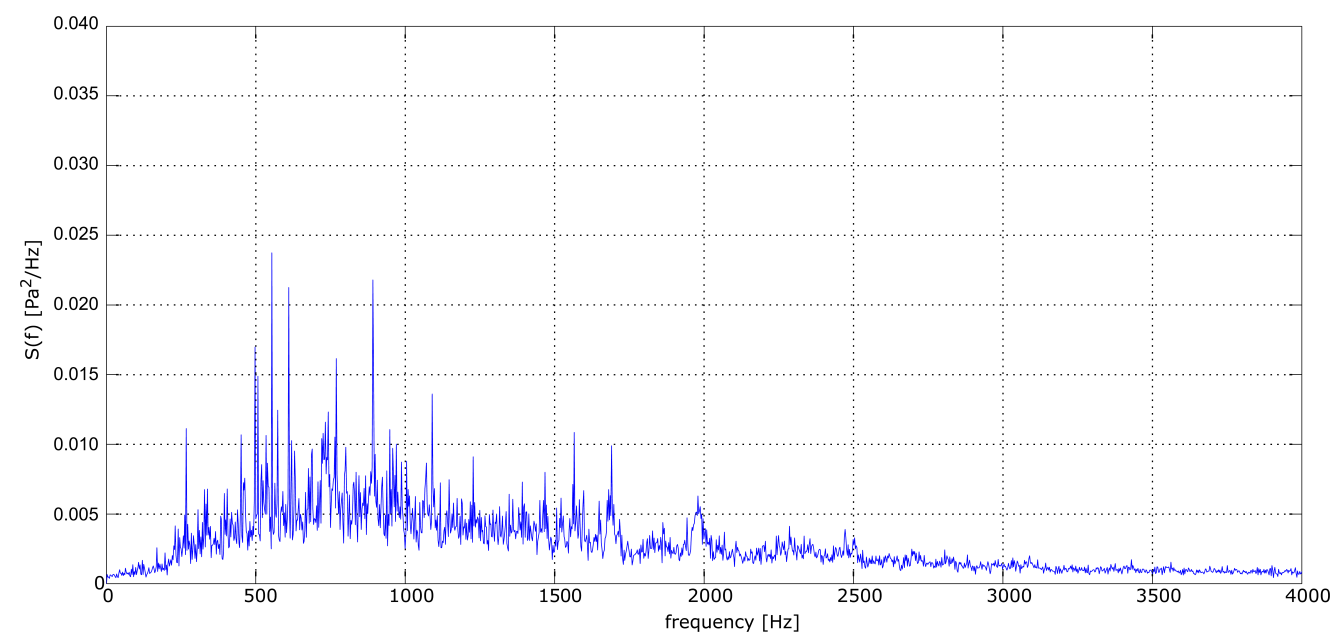

Fig. 8. Power spectrum density determined in asynchronous averaging procedure for tires with non-directional tread pattern with nominal pressure. 


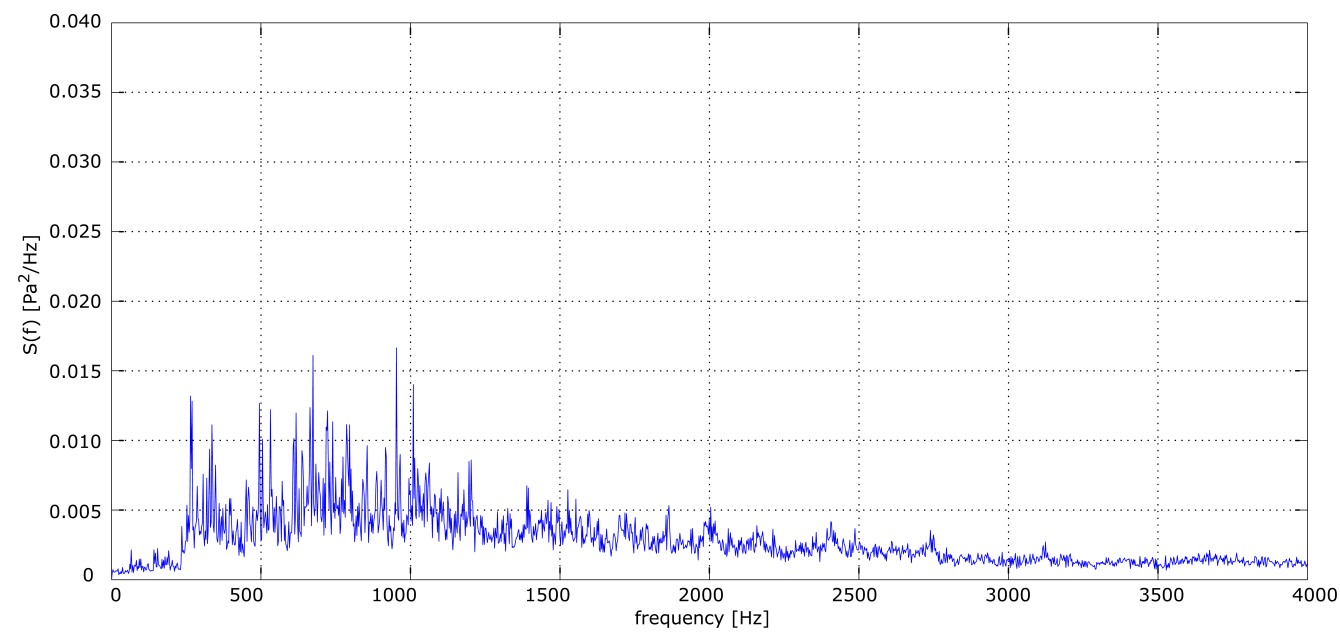

Fig. 9. Power spectrum density determined in asynchronous averaging procedure for tires with non-directional tread pattern with undervalued pressure.

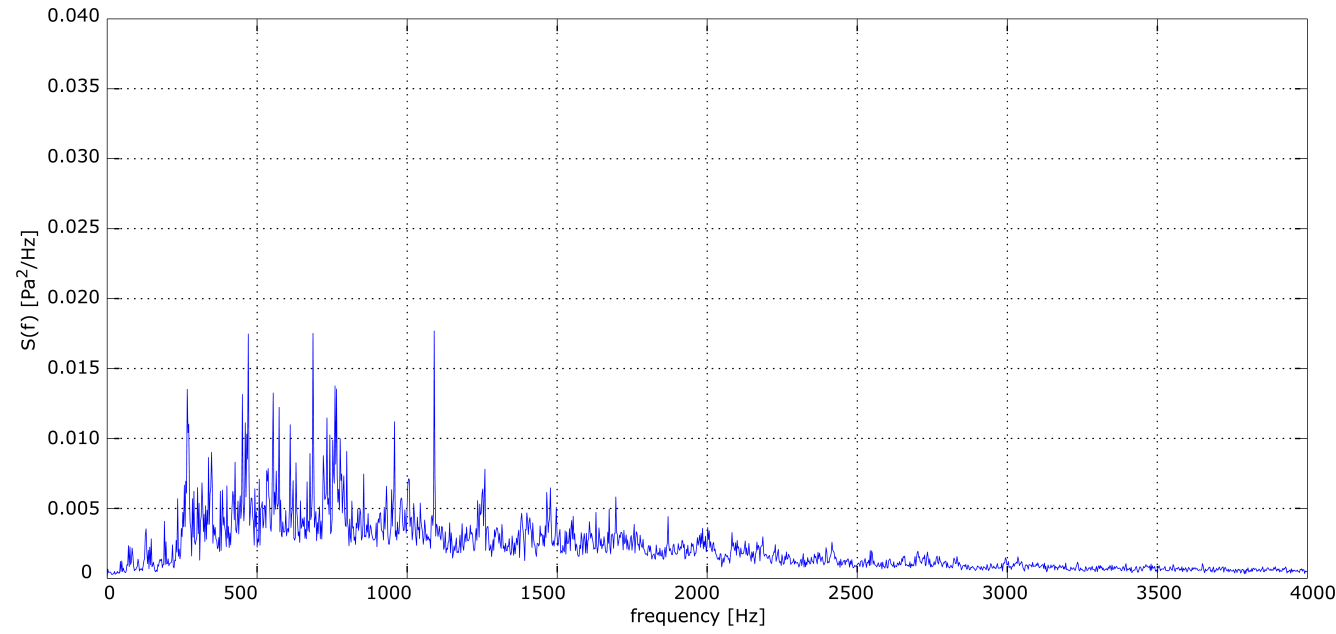

Fig. 10. Power spectrum density determined in asynchronous averaging procedure for tires with non-directional tread pattern with overvalued pressure.

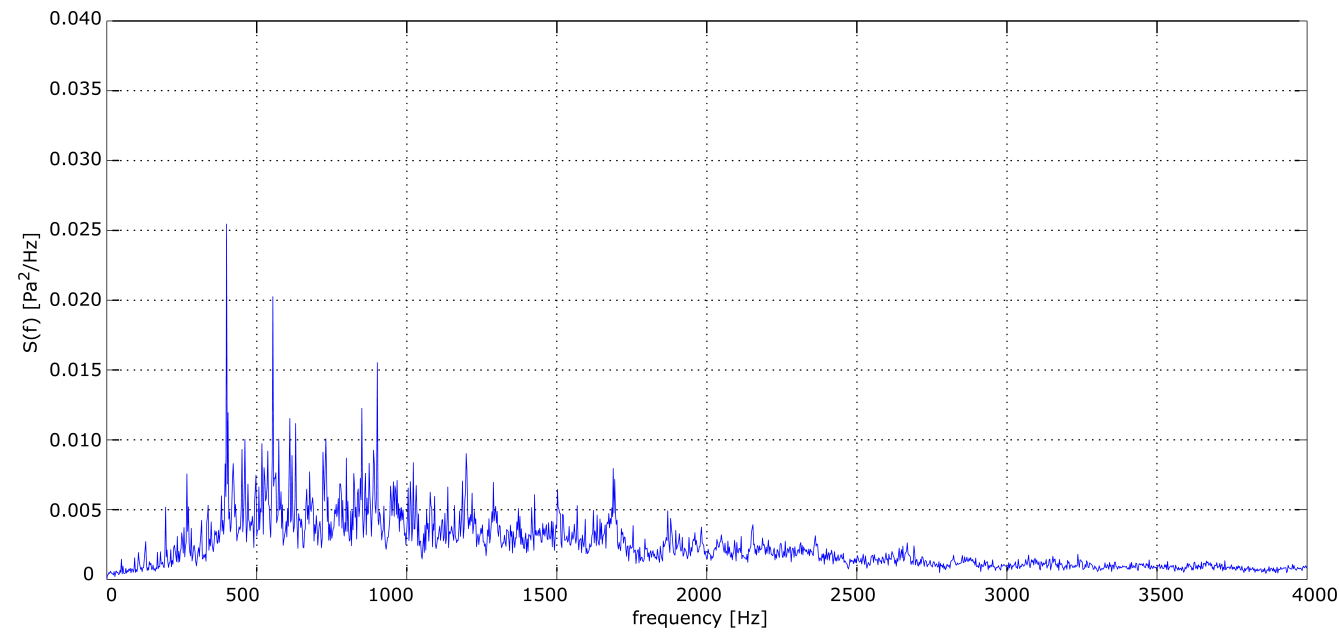

Fig. 11. Power spectrum density determined in asynchronous averaging procedure for tires with directional tread pattern with nominal pressure. 


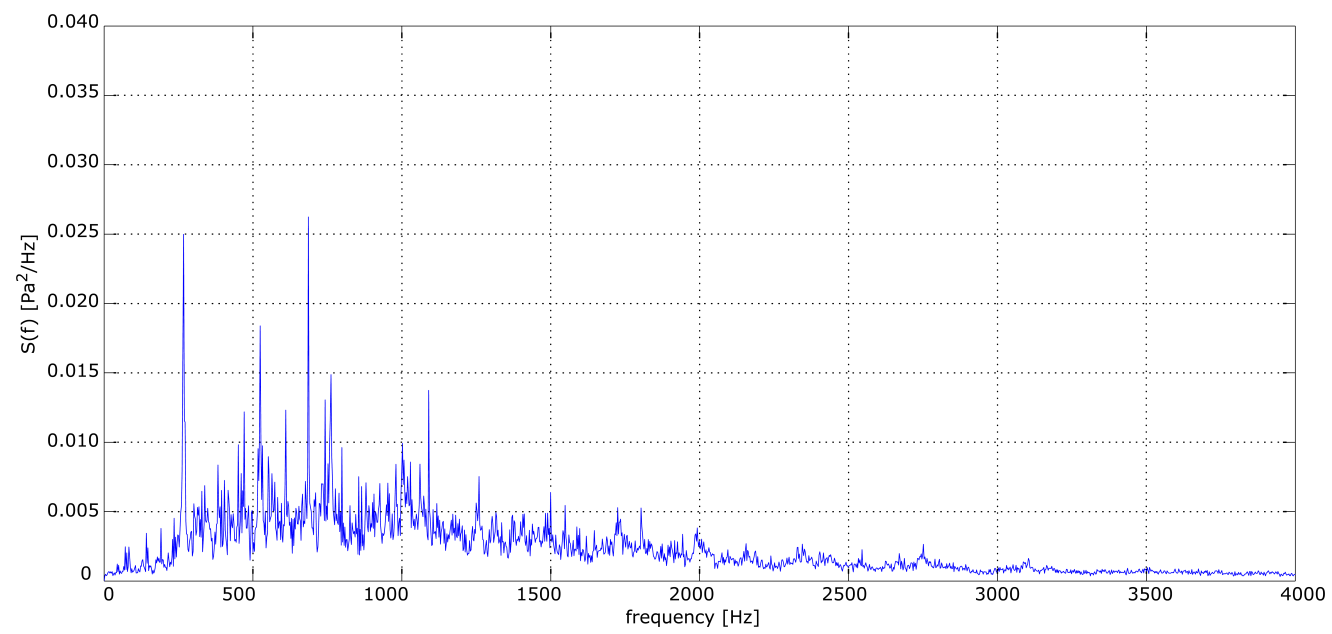

Fig. 12. Power spectrum density determined in asynchronous averaging procedure for tires with directional tread pattern with undervalued pressure.

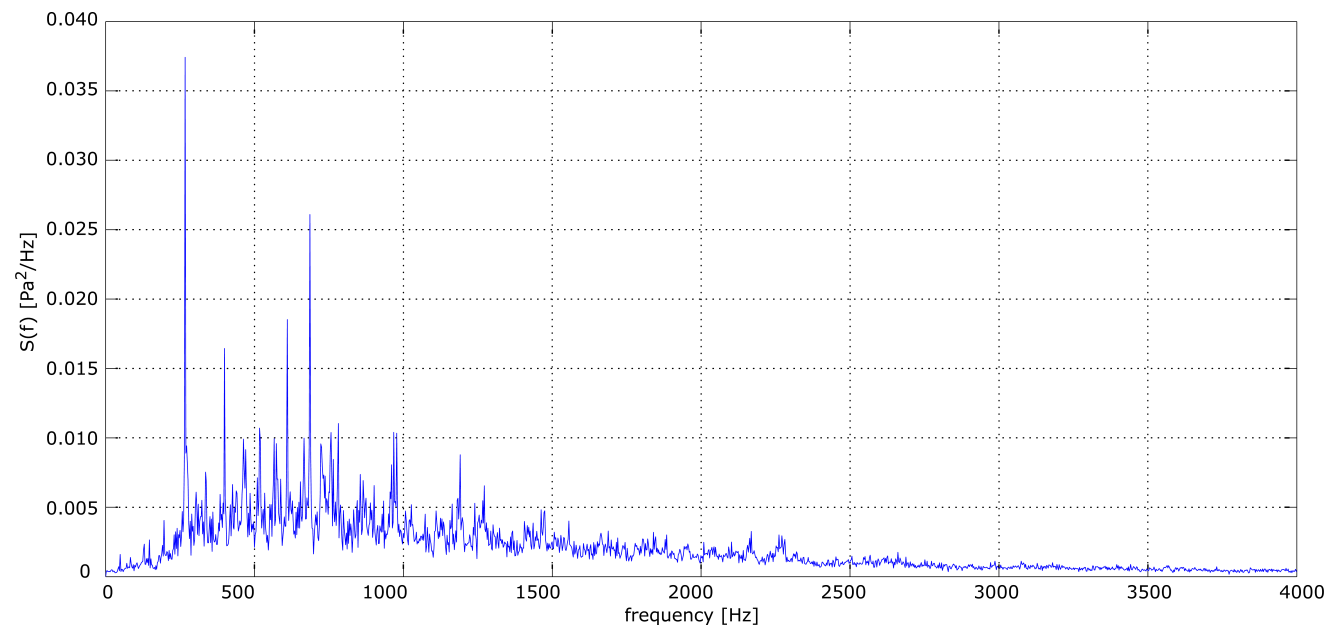

Fig. 13. Power spectrum density determined in asynchronous averaging procedure for tires with directional tread pattern with overvalued pressure.

for the two types of the tested tires with directional and non-directional tread. According to the adopted goal of the research measurements of acoustic emission of tires in the conditions of the nominal pressure recommended for the set type of tire - and the overvalued and undervalued pressure were carried out. The selected results were obtained at the measuring point No. 3 .

Based on the survey and the obtained results it can be stated that in the spectrum of the noise emitted by the tires frequency components are dominant. For non-directional tire the frequency structure consists of more components which for the movement speed adopted in the studies are situated in the higher frequency range than in the directional tire. In the case of a tire with a directional tread acoustic emission energy is more associated with specific frequency components. Thus, it is possible to build systems of noise reduction which are largely deterministic (DĄBROWSKI et al., 2015; JinN-TONG et al.,
2015; O'Boy et al., 2009). Radial vibrations of the tread elements are probably one of the basic mechanisms of generating noise for most types of tires. This is indicated by observing the effect of small modifications of tread on the level and noise spectrum. They also promote other mechanisms, such as the resonant vibration of the air columns enclosed in the grooves of the tread.

In the case of a tire, however, there are several complications associated with non-linear type characteristics of the composite rubber/cord thread. Elastic and damping properties of pneumatic wheel are possible to be described purely by way of non-linear mathematical functions. When changing a tire pressure it comes to changes in the characteristics which are reflected in the frequency structure of noise.

\section{Summary}

Currently sold tires have information only about global noise (sound power level). The study developed 
a method of analysing frequency components of noise generated by the wheels of vehicles, which allows getting objective results. The developed method is based on the use in research of laboratory station, which allowed obtaining results independent of the influence of the type of road surface on the emission of sound while driving. The results should be considered as an introduction to further research to complement global measures of noise used to describe the acoustic characteristics of the tires of the complex frequency response. In the experiment the tire contacts the elastic rubbercord belt. It may be distortion of spectrum with respect to the actual operating conditions. However, the proposed method is a comparative tool and should be treated as such.

\section{References}

1. Anfosso-Lédée F., Pichaud Y. (2007), Temperature effect on tyre - road noise, Applied Acoustics, 68, 1, 1-16, doi: 10.1016/j.apacoust.2006.06.001.

2. BURDZIK R. (2014), Identification of structure and directional distribution of vibration transferred to carbody from road roughness, Journal of Vibroengineering, 16, 1, 324-333.

3. Burdzik R., Konieczny L. (2013), Research on structure, propagation and exposure to general vibration in passenger car for different damping parameters, Journal of Vibroengineering, 15, 4, 1680-1688.

4. Byoung S.K., Gi J.K., TAE K.L. (2007), The identification of sound generating mechanisms of tyres, Applied Acoustics, 68, 114-133.

5. CABAn J., Droździel P., BARTA D., LiŠČÁK Š. (2014), Vehicle tire pressure monitoring systems, Diagnostyka, 15, 3, 11-14.
6. Cioch W., KnapiK O., Leskow J. (2013), Finding a frequency signature for a cyclostationary signal with application to wheel bearing diagnostics, Mechanical Systems and Signal Processing, 38, 1, 55-64.

7. DąBrowski Z., Zawisza M. (2015), The choice of vibroacoustic signal measures in mechanical fault diagnosis of diesel engines, Solid State Phenomena, 236, 220-227.

8. Ibarra D., Ramírez-Mendoza R., López E. (2017), Noise emission from alternative fuel vehicles: Study case, Applied Acoustics, 118, 58-65.

9. Jinn-Tong C., Fu-Yuan T. (2015), Application of a pattern recognition technique to the prediction of tire noise, Journal of Sound and Vibration, 350, 30-40.

10. KATUnin A. (2016), Application of time-frequency distributions in diagnostic signal processing problems: A case study, Diagnostyka, 17, 2, 95-103.

11. Michelin (2002), Tire - mechanical and acoustic comfort [in Polish: Michelin: Opona - komfort mechaniczny i akustyczny], Societe de Technologie Michelin.

12. O'Boy D.J., Dowling A.P. (2009), Tyre/road interaction noise - Numerical noise prediction of a patterned tyre on a rough road surface, Journal of Sound and Vibration, 323, 270-291.

13. Rustighia E., Elliotta S.J., Finnvedenb S., Gulyasc K, Mocsaic T., Dantid M. (2008), Linear stochastic evaluation of tyre vibration due to tyre/road excitation, Journal of Sound and Vibration, 310, 11121127.

14. Wodecki J., Stefaniak P., Obuchowski J., WyloMANSKA A., ZimRoz R. (2016), Combination of principal component analysis and time-frequency representations of multichannel vibration data for gearbox fault detection, Journal of Vibroengineering, 18, 4, 21672175. 